\title{
Legendagem de campanhas políticas e de propagandas de anúncios publicitários televisivos brasileiros: uma pesquisa de recepção
}

\author{
Vera Lúcia Santiago Araújo \\ Universidade Estadual do Ceará \\ verainnerlight@uol.com.br
}

Silvia Malena Modesto Monteiro

Universidade Estadual do Ceará

malenammonteiro@gmail.com

Patrícia Araújo Vieira

Universidade Federal do Ceará pattivieira477@yahoo.com.br

\section{Resumo}

Esta pesquisa piloto de recepção discute a questão da legendagem de campanhas políticas e de propagandas de anúncios publicitários na televisão brasileira sob a ótica de informantes surdos da cidade de Fortaleza. A problemática da pesquisa é: qual a visão dos surdos na cidade de Fortaleza quanto à legendagem de campanhas políticas e de propagandas de anúncios publicitários na TV, atualmente? A pesquisa pode ser definida como exploratória e qualitativa, baseada na análise e na interpretação de fatos por meio de observação, questionários e relatos, tendo seus dados analisados indutivamente. Os participantes são duas informantes surdas, ambas professoras, uma universitária e a outra de uma escola pública de surdos. Por meio de relatos retrospectivos filmados elas apresentaram sua visão acerca das referidas legendagens oferecidas pela televisão brasileira atualmente. Segundo elas, as legendas e a janela de Libras são importantes para os surdos terem acesso à informação, mas essas técnicas ainda não traduzem suficientemente as informações auditivas e visuais das programações. Dentre os problemas detectados estão: cor da fonte; legendas closed caption consideradas longas e rápidas; e poluição visual na tela. As informantes também se mostram 
insatisfeitas com as legendas pop-on e roll-up, em geral utilizadas na TV, afirmando que precisam ser melhoradas.

Palavras-chave: Legendagem. Surdos. Campanha política. Propaganda.

\begin{abstract}
The present pilot reception research aims at discussing the subtitling process of political campaigns and advertisements for the Brazilian television. Two deaf informants from the city of Fortaleza participate in the research. The research question is: how do deaf people in Fortaleza see the subtitling process of political campaigns and advertisements in the Brazilian television? This is an exploratory and qualitative research, based on the analysis and interpretation of facts through observation, questionnaires and reports and on inductive analysis. The participants are two deaf women, a university professor and a public school teacher. Through filmed interviews and retrospective reports, they present their view about the current subtitling process offered by the Brazilian TV. According to them, the subtitles and the LIBRAS window are important for the deaf to access information, but these techniques still need improvement to adequately translate the information for them. Some of the issues mentioned by the informants are: the subtitle font colour; too long and fast closed caption subtitles; and the visual pollution on the screen. They also report not be satisfied with the pop-on and roll-up subtitles, claiming that these need to be improved.
\end{abstract}

Keywords: Subtitling. Deaf. Political Campaign. Advertisement.

\title{
1 Introdução
}

Os surdos brasileiros vivem em um país que tem como língua oficial a portuguesa, onde a maioria de sua população é ouvinte e falante dessa língua. Por terem a Língua Brasileira de Sinais (Libras) como sua primeira língua (L1), a língua portuguesa passa a ser para os surdos brasileiros a segunda língua (L2). Contudo, há outro grupo que também se enquadra no grupo da surdez, mas não tem a Libras como L1, e sim a língua portuguesa: os ensurdecidos. Esse grupo, de forma geral, ficou surdo após seu período de alfabetização em língua portuguesa. Alguns ainda não são sinalizados, mas leem e compreendem textos em língua portuguesa. De acordo com Neves (2005), a pessoa surda é aquela que possui uma séria e profunda perda auditiva (acima de 60 decibéis); por sua vez, a pessoa ensurdecida é 
aquela que possui perda auditiva moderada (entre 15 e 60 decibéis). A pesquisa aqui proposta trabalhou especificamente com pessoas surdas. Isso ocorreu principalmente pela facilidade de encontrar voluntários para participar da pesquisa, o que é mais comum na comunidade surda do que na comunidade ensurdecida. Vale lembrar que se trata de uma pesquisa piloto, com número de participantes reduzido (dois informantes), portanto seus resultados não podem ser considerados conclusivos, mas apenas uma contribuição para pesquisas futuras.

O tipo de legendagem feita para o público surdo é conhecido como Legendagem para Surdos e Ensurdecidos (LSE). A LSE é uma modalidade de tradução audiovisual (TAV) que visa a fornecer a tradução da trilha sonora de produções audiovisuais, tais como filmes, programas de TV, peças de teatro e eventos ao vivo. O objetivo é facilitar o acesso de surdos/ensurdecidos a esse tipo de produção.

Em 27 de junho de 2006 o governo brasileiro promulgou a Portaria n. 310, que estabelece que todos os programas brasileiros de TV aberta devem ser acessíveis a surdos/ensurdecidos e cegos/parcialmente cegos por meio de legendagem/Libras e audiodescrição até o ano de 2018. No Brasil, desde 1997 os programas jornalísticos começaram a ser traduzidos por legendas para surdos e ensurdecidos (LSE) dos tipos roll-up e pop-on. ${ }^{1}$ Esses tipos de legenda são produzidos em programas ao vivo e não apresentam sincronismo entre fala, imagem e legenda, o que pode dificultar a leitura e a compreensão dos diálogos. Hoje, as legendas para surdos e ensurdecidos podem ser visualizadas tanto em programas jornalísticos como em programas de entretenimento, tais como novelas, filmes, seriados, etc. oferecidos pela televisão brasileira. $\mathrm{O}$ acesso às legendas fechadas é possível quando é acionado o botão caption ou subtitle nos controles dos aparelhos mais modernos. Ainda assim, tais modelos podem não atender às necessidades de surdos e ensurdecidos (ARAÚJO, 2004; 2007; 2008). Por essa razão, são necessárias cada vez mais pesquisas de recepção com surdos para que os modelos possam ser melhorados.

${ }^{1}$ A legenda roll-up é aquela cujas linhas sobem da parte inferior da tela da $\mathrm{TV}$, podem ser exibidas em até quatro linhas por vez. A legenda pop-on é aquela cujas frases surgem como um todo. É o tipo de legendagem usado em programas pré-gravados (ARAÚJO, 2005).

Horizontes de Linguística Aplicada, ano 12, n. 1, 2013 
No que diz respeito às campanhas político-partidárias na $\mathrm{TV}, \mathrm{o}$ Tribunal Superior Eleitoral definiu que a partir de 2006 todos os partidos devem oferecer, durante a campanha eleitoral, uma das duas formas de acesso (legendagem ou Libras) ao surdo brasileiro (ARAÚJO, 2009). Atualmente, as legendas feitas nessas campanhas obedecem à portaria, mas algumas delas podem não atender às necessidades de surdos/ensurdecidos brasileiros. Pesquisas (FRANCO; ARAÚJO, 2003; ARAÚJO, 2004; 2005; 2007; 2008), entre elas as realizadas pelo grupo Legendagem e Audiodescrição (Lead) da Universidade Estadual do Ceará, sugerem que essas legendas precisam de alterações técnicas e estilísticas para que possam garantir a acessibilidade de seu público. No caso das campanhas políticas, estamos falando de legendas abertas e pop-on, que são pré-gravadas e não precisam ser acionadas pelo botão closed caption da TV. Na verdade, na maioria das vezes as legendas disponibilizadas em campanhas políticas na TV não seguem os padrões preconizados pelos pesquisadores da área, mais especificamente daqueles que se dedicam à Legendagem para Surdos e Ensurdecidos (LSE). Em pesquisas recentes, o grupo Lead propôs parâmetros que poderão guiar as legendas de campanhas políticas feitas diretamente para o público de surdos/ensurdecidos do país. São eles:

1) uso de letras brancas em um fundo preto devido à grande quantidade de informações visuais na tela e ao pouco espaço;

2) versão condensada da fala original se a velocidade da fala for superior a 180 palavras por minuto (ppm);

3) a quebra de linhas/segmentação deve seguir o ritmo da fala, adotando-se critérios visuais, retóricos e linguísticos;

4) uso de itálico para marcar a voz off-screen;

5) uso de letras maiúsculas para legendar informações diegéticas, tais como manchetes, títulos de livros, nomes de prédios, etc.;

6) uso de colchetes para identificar falantes e efeitos sonoros;

7) a legenda deve ser apresentada em apenas uma linha; 
8) velocidade de leitura: 145, 160 ou 180 ppm (ARAÚJO, 2009; ARAÚJO; NASCIMENTO, 2011; ARAÚJO; VIEIRA; MONTEIRO, 2013)

Vale ressaltar que os referidos parâmetros já são resultado de mudanças feitas pela equipe do Lead nos parâmetros antes existentes (ARAÚJO, 2009), os quais foram sugeridos pela equipe de surdos (Centro de Apoio ao Surdo - CAS) que participou de pesquisas anteriores (ARAÚJO; NASCIMENTO, 2011; ARAÚJO; VIEIRA; MONTEIRO, 2013). As mudanças dizem respeito a três aspectos: uso de letras brancas em um fundo preto em vez de letras amarelas em um fundo transparente; apresentação das legendas em uma só linha em vez de duas; quebra de linhas segue o ritmo da fala, adotando-se somente critérios retóricos e linguísticos. Nesse caso, o critério visual adotado anteriormente não é usado aqui, pois cortes e movimentos de câmera não são tão comuns na legendagem de programas políticos. Porém, esses parâmetros são uma proposta. Eles não são, de forma geral, praticados pelos responsáveis pela legendagem de campanhas políticas no Brasil. O que se vê, na maioria das vezes, são transcrições da fala do candidato, e questões como tamanho da letra, tipo de letra, uso do itálico, etc. mudam bastante entre as campanhas dos diferentes partidos. O grupo Lead vem lutando para que mudanças ocorram e os parâmetros sejam adaptados à realidade dos surdos da melhor forma possível.

Outro gênero televisivo visto por muitos brasileiros são as propagandas de anúncios publicitários televisivos. Usadas com o propósito de persuadir, chamar a atenção para o produto em questão, elas têm apresentado inovações em suas exibições. Das simples propagandas que apenas ofereciam o produto, elas passaram a apresentar textos com diálogos e situações bem próximas da realidade dos consumidores. Também costumam, nas situações apresentadas e nos diálogos, provocar quebra de esquemas, o que pode causar uma inicial estranheza ao leitor. As propagandas comerciais atuais duram em média 30 segundos. Algumas propagandas comerciais já obedecem à Portaria n. 310 e apresentam as legendas fechadas na modalidade pop-on, mas ainda em um número reduzido.

A pesquisa aqui apresentada justifica sua relevância social na discussão sobre acessibilidade, de modo geral, e sobre acessibilidade 
de surdos/ensurdecidos à televisão, de modo mais específico. Justificase também por ser uma contribuição aos estudos de tradução audiovisual, os quais se vêm desenvolvendo cada vez mais. Ela vem, portanto, juntar-se a outros trabalhos sobre recepção de legendagem (D'YDEWALLE, 1987; DE LINDE; KAY, 1999) e também aos trabalhos desenvolvidos pelo grupo Lead da Universidade Estadual do Ceará, buscando fomentar o desenvolvimento de pesquisas nessa área.

Nos próximos parágrafos apresentamos o referencial teórico que serviu como base para a pesquisa. Basicamente trabalhamos com os conceitos de legendagem e de pesquisa de recepção, destacando seus aspectos importantes, principalmente no que diz respeito ao trabalho aqui apresentado.

\section{Legendagem}

A legenda é um recurso visual que permite aos ouvintes de línguas estrangeiras, aos surdos e aos ensurdecidos, em especial, terem acesso aos meios de comunicação e entretenimento audiovisuais. Há, portanto, dois tipos de legendas: a intralinguística (para pessoas surdas e ensurdecidas) e a interlinguística (para espectadores ouvintes, usada em filmes ou programas de entretenimento em língua estrangeira). De acordo com De Linde e Kay (1999), apesar das diferenças que esses dois tipos de legenda apresentam, elas têm um aspecto em comum: o mesmo contexto audiovisual. Contudo, seus objetivos diferem em alguns aspectos. A legenda intralinguística se propõe, primordialmente, a traduzir tanto os diálogos como os recursos audiovisuais, tais como áudios componentes, incluindo aspectos da trilha sonora. $^{2}$

Araújo (2008, p. 60) define a Legendagem para Surdos e Ensurdecidos (LSE) como "um recurso de acessibilidade para espectadores surdos que consiste na inserção de legendas em produções audiovisuais". Essas legendas, conforme a autora, são

${ }^{2}$ Para expor na legenda o aspecto da trilha sonora, os legendadores utilizam recursos gráficos, como uma nota musical, ou optam por escrever o tipo de música entre colchetes.

142 Horizontes de Linguística Aplicada, ano 12, n. 1, 2013 
diferentes das legendas para ouvintes, pois apresentam concepções técnicas diferentes. Na LSE são introduzidas informações adicionais do áudio, além de informações que identificam quem está falando. Tais informações geralmente são acrescentadas entre colchetes antes da primeira letra da legenda da fala do personagem em questão. Nas legendas para ouvintes geralmente se usa o modelo europeu de legendas com no máximo duas linhas e tempo de duração de 4 a 6 segundos. Essas legendas são condensadas, colaborando com a velocidade de leitura, e apresentam-se na cor branca ou amarela, sem identificação de quem está falando. A duração de segundos e caracteres $^{3}$ é distribuída da seguinte forma: 1 segundo (meia legenda) $=$ $14,15,16$ caracteres; 2 s (uma linha de legenda) $=28,30$ ou 32 caracteres; $3 \mathrm{~s}$ (uma linha e meia de legenda) $=42,45$ ou 48 caracteres; $4 \mathrm{~s}$ (duas linhas de legenda ou legenda cheia) $=56,60$ ou 64 caracteres (ARAÚJO, 2008).

Pode-se afirmar que muitos surdos apresentam dificuldade para ler textos em língua portuguesa - L2, contudo eles são capazes de lê-los, mas a velocidade e a eficiência são muitas vezes inferiores às dos ouvintes falantes da língua portuguesa como primeira língua (L1) (VIEIRA, 2009). No que diz respeito às legendas, quando elas apresentam sincronia com imagem, diálogo, conteúdo, trilha sonora, velocidade e segmentação, elas contribuem para a compreensão leitora de um todo.

A leitura de legendas envolve muito mais do que a compreensão de palavras e frases. De acordo com Perego (2008), a leitura é uma atividade de percepção cognitiva complexa que consiste na aquisição de informações com base na escrita. Em relação à leitura de legendas, a autora afirma que os surdos estão em desvantagem se comparados aos ouvintes por diversas razões. Os ouvintes têm o input gramatical durante a leitura e a compreensão. Conseguem, por terem a língua portuguesa como língua materna, preencher com mais facilidade as lacunas deixadas durante a leitura por não conseguirem acompanhar totalmente a velocidade da legenda. ${ }^{4}$ Em virtude da dificuldade que os

${ }^{3}$ Espaço e pontuação estão incluídos nos caracteres.

${ }^{4}$ Os ensurdecidos podem ter também vantagens se comparados aos surdos, pois se eles perderam a audição já adultos, o português ainda será sua primeira língua.

Horizontes de Linguística Aplicada, ano 12, n. 1, 2013 
surdos podem apresentar para ler legendas em L2 é que alguns programas, principalmente as propagandas políticas, usam a janela de Libras $^{5}$ como reforço às legendas. Tal recurso em outros tipos de programação (filmes, novelas, séries) provavelmente não tem a mesma eficiência que as legendas. $\mathrm{O}$ fato de esses programas usarem vários diálogos e situações visuais na mesma screen (tela) poderia prejudicar a leitura da imagem durante o programa, no caso da janela de Libras. Dessa forma, as pesquisas devem continuar buscando melhores recursos para legendas apropriadas aos surdos.

Perego (2003, p. 65) afirma que ao traduzirmos informações da língua falada para a escrita há perdas de muitas "características prosódicas inerentes ao código falado, tais como tom e modulação da voz, acentos e marcadores linguísticos (isto é, peculiaridades gramaticais) que são importantes indicadores sociolinguísticos". Para Ivarsson (1992), as convenções tipográficas e as pontuações podem reduzir ou minimizar essas perdas do diálogo falado.

Quanto ao público-alvo das legendas, De Linde e Kay (1999) observam que elas não devem seguir um mesmo padrão em toda a programação e para as diferentes faixas etárias. As autoras afirmam que:

[...] as legendas para adultos diferem das legendas para crianças na capacidade linguística. Em geral, a legenda para crianças tem uma visualização mais longa, o que implica numa edição com mais detalhes do diálogo, a fim de manter-se dentro da estrutura original do diálogo (p. 52).

Logo, as variáveis observadas nas legendas, tais como sincronia entre imagem e diálogo, sincronia entre imagem e legenda, extensão e edição, dependem do tipo de programa, da faixa etária do espectador e das características desse espectador: se surdos, ensurdecidos ou ouvintes.

Aprofundando a questão dos surdos e ensurdecidos e sua realidade, os autores dividem a comunidade surda em dois grupos: os que nascem surdos e os que adquiriram perda de audição ao longo da vida. Os primeiros em geral têm boa habilidade com a língua de sinais

\footnotetext{
${ }^{5}$ Recurso usado por vários programas. Geralmente se situa na parte inferior da tela, em um espaço pequeno, com um intérprete de Libras.

$144 \quad$ Horizontes de Linguística Aplicada, ano 12, n. 1, 2013
} 
e têm um ritmo de leitura mais lento. Os segundos apresentam uma velocidade de leitura maior, até porque em geral foram criados na comunidade ouvinte, seguindo suas regras. Para os autores, os surdos desde o nascimento têm, além de um ritmo de leitura mais lento, uma amplitude menor de informações devido à forma como foram educados. De qualquer modo, eles afirmam que é essencial que surdos e ensurdecidos tenham tempo para ler as legendas e associá-las à imagem na tela.

Ivarsson e Caroll (1998) mencionam o fato de que em muitos países a velocidade em que aparecem as legendas desrespeita as necessidades de surdos e ensurdecidos - uma realidade também no Brasil. Os autores lembram a responsabilidade que as empresas que produzem legendas devem ter não só com surdos e ensurdecidos, mas também com crianças em fase de aprendizagem da leitura, imigrantes que não dominam a língua, pessoas com problemas de visão, idosos, entre outros. Trata-se de uma questão de responsabilidade com todas as categorias de telespectadores.

Os autores apresentam as necessidades dos surdos e ensurdecidos no que diz respeito a legendas:

1) Informações adicionais que os ajudam a compreender o que está se passando ("passos na escada", "um grito de terror", etc.).

2) Informações sobre quem está falando naquele momento (usar cores diferentes para facilitar).

3) A velocidade de leitura varia muito de pessoa para pessoa. O ideal seria que todos tivessem opções e pudessem escolher seu ritmo ideal. De Linde e Kay (1999) também comentam a questão da velocidade de leitura e afirmam ser difícil estabelecer uma velocidade ideal para leitores surdos. Segundo eles, há muitas variáveis que afetam a leitura tanto de ouvintes quanto de surdos/ensurdecidos, tais como o tópico do texto, o interesse do leitor, etc. Além disso, surdos e ensurdecidos são grupos diversos que apresentam diferenças no grau de surdez, na primeira língua (falada ou língua de sinais) e nas estratégias e nas habilidades de leitura.

Vale ressaltar, no entanto, que, além da velocidade, um parâmetro que se vem destacando nas pesquisas em LSE é o da 
segmentação. Esta consiste, basicamente, na subdivisão de legendas, ou seja, é a decisão acerca do início e do final de uma legenda (CHAVES, 2012). Ela deve buscar respeitar o corte ou a mudança de cena, o fluxo da fala e a sintaxe, contendo um pensamento completo sempre que possível. Atualmente, a segmentação tem sido bastante discutida nos estudos da TAV, suscitando cada vez mais pesquisas quanto à sua importância na LSE.

Comentando o conceito e a categorização da segmentação, Araújo e Chaves (2012) afirmam que a segmentação é o parâmetro da legendagem relacionado à divisão e à distribuição de legendas, que pode ocorrer entre duas legendas diferentes ou na mesma legenda (quebra de linha). Segundo as autoras, para que uma fala seja segmentada em legendas podem ser adotados três critérios:

1) linguístico: pautado pela sintaxe, ou seja, cada linha de legenda deve conter um pensamento (o mais completo possível);

2) retórico: pautado pelo fluxo da fala, ou seja, após uma pausa, uma nova legenda deve ser produzida;

3) visual: pautado pelo corte de cena, ou seja, sempre que a mudança de cena coincidir com o tempo de saída de uma legenda, esta não deve durar até a cena seguinte. As autoras afirmam que determinadas pesquisas (KARAMITROGLOU 1998; DÍAZ-CINTAS; REMAEL, 2007, p. 1) sugerem que "uma segmentação fora desses padrões pode causar problemas de recepção, pois o espectador pode se cansar mais rapidamente e perder o interesse em continuar assistindo ao filme devido ao esforço despendido". Pode-se afirmar, então, que as pesquisas sobre LSE têm cada vez mais abordado a questão da segmentação como aspecto essencial no processo de recepção de legendas pelos surdos.

A seguir apresentamos informações acerca de pesquisas de recepção, considerando que esta pesquisa se encaixa nessa categoria. Vale ressaltar que há muito mais a ser dito sobre o assunto, e mais pesquisas devem ser desenvolvidas a fim de fomentar ainda mais essa discussão. 


\section{Pesquisa de recepção}

Segundo Lopes (2011), uma análise dos relatórios sobre pesquisa de recepção na América Latina demonstra uma preocupação com o modo de participação dos receptores diante das mensagens emitidas pelos meios de comunicação. Conforme a autora, essa preocupação ultrapassa a visão positivista de um receptor decodificador para uma proposta que leve em consideração o modelo de mediação de Martín-Barbero calcado no tripé comunicação-culturapolítica. Nesse modelo, o foco não seria apenas descrever as situações de mediação, mas propiciar meios para compreendê-la e ampliá-la e qualificação com vistas a uma cidadania inclusiva. De acordo com Barsi-Lopes (2008, p. 6): "O telespectador é ativo porque produz sentidos sobre aquilo que "recebe' dos meios de comunicação". Portanto, é importante considerar que os telespectadores para os quais os meios de comunicação se dirigem não são figuras passivas. Além disso, essa relação não se processa apenas enquanto a televisão está ligada, mas, como um processo contínuo, ela abrange outras esferas da vida do telespectador.

Dos meios de comunicação mais populares, a televisão brasileira, por muitos anos, tem sido um dos mais buscados pelos cidadãos brasileiros para obter informações. Para o grupo de pessoas ouvintes ela apresenta uma mensagem visual e auditiva, mas para o grupo dos que não escutam ela parece ainda estar aquém de atender às suas necessidades. Os recursos tecnológicos usados em algumas programações brasileiras, tais como closed caption e respeaking ${ }^{6}$ aparentemente precisam de melhorias para atender a comunidade surda.

Levando em consideração a falta de legendas apropriadas aos surdos e aos ensurdecidos nas programações televisivas brasileiras é que reiteramos para o contexto da comunidade surda o que antes foi exposto por Barsi-Lopes $(2008$, p. 2) para o contexto dos ouvintes:

\footnotetext{
${ }^{6}$ Respeaking, conforme Ribas e Romero Fresco (2008), é o processo em que o profissional ouve o texto e refala. A entrada vocal é processada por um software de reconhecimento da fala, produzindo assim uma legenda em tempo real.
}

Horizontes de Linguística Aplicada, ano 12, n. 1, 2013 
$O$ sentimento de ser cidadão, de pertença a uma comunidade, antes praticado pelas relações "face-a-face", pelas identidades locais, pelas interações territorializadas, $e$, principalmente, pela atuação do Estado, passam a ser, também, intercambiados pela mídia. Não podemos deixar de perceber em nossa sociedade contemporânea o fato de que o fenômeno da midiatização parece afetar todas as práticas sociais existentes. [...] Ao indivíduo atual incide, também, a necessidade de existência pública, de fazer ser visível na sociedade, de transitar e de ser contemplado nas relações de sociabilidade hodiernas, tão impregnadas pelo fenômeno da midiatização.

Mediante essas afirmações focamos neste artigo a entrevista de recepção, mais especificamente em relatos retrospectivos gravados, levando em consideração o modelo de entrevista comumente usado nas pesquisas sociológicas em etnografia. Para Guber (2004, p. 203): “A entrevista é uma das técnicas mais apropriadas para se ter uma aproximação do universo de significação dos sujeitos". Por isso, antes de propor modelos de legendas apropriados aos surdos é importante conhecer o contexto em que estão inseridos e compreender de que forma as técnicas atuais de legendagem podem contribuir para o acesso às informações por meio dos instrumentos de comunicação.

O objetivo da entrevista de pesquisa de recepção não foi apenas ter questionamentos respondidos ou hipóteses confirmadas. Foi também buscar compreender, tanto quanto possível, o contexto cultural de um grupo social, no caso os surdos, além das perspectivas desses sujeitos. Como ressaltou Guber, com base na entrevista, nós, pesquisadores, reconhecemos que "o universo dos informantes é diferente do mundo do investigador" (2004, p. 207). Portanto, partimos de uma conversa buscando extrair o máximo de informações relacionadas a como os surdos lidam com as programações televisivas, legendadas ou não. Como o tempo para o desenvolvimento das entrevistas foi curto (uma ou duas horas aproximadamente), procuramos conduzir os informantes ao tema televisão. Contudo, procuramos levar em consideração o modelo da pesquisa de campo antropológica, ou seja, como investigadores procuramos formular 
perguntas, e o que obtínhamos como resposta se transformava em novas perguntas, pois, conforme Guber (2004, p. 15):

Categorias, conceitos, prioridades e interesses do investigador se mantêm, mas se relativizam. Esse processo demanda tempo, não no sentido formal, mas no sentido de espera paciente (e não passiva) em que o investigador relaciona, hipotetiza, confirma e refuta explicações.

Com base nas respostas obtidas na entrevista começamos a compreender melhor as reais necessidades dos surdos para o desenvolvimento de um modelo de legendas confortável para eles em relação a programas políticos e propagandas televisivas de anúncio publicitário, conforme será discutido mais adiante. Assim, a pesquisa de recepção tem contribuído para uma maior aproximação entre o objeto de pesquisa (modelos de legendagem) e os sujeitos responsáveis pelo desenvolvimento deste estudo.

\section{Metodologia}

\subsection{Tipo de pesquisa}

Esta pesquisa visa a discutir a recepção das legendas de campanhas políticas e de propagandas de anúncios publicitários televisivos por dois indivíduos surdos da cidade de Fortaleza. Trata-se de uma pesquisa piloto que pode servir de base para pesquisas mais aprofundadas e com mais participantes no futuro. A pesquisa pode ser definida como exploratória e qualitativa, baseada na análise e na interpretação de fatos por meio de observação, questionários e relatos, tendo seus dados analisados indutivamente.

No que diz respeito aos procedimentos, trata-se de uma pesquisa de campo, visto que a compreensão da recepção de legendas em programas televisivos pelos sujeitos foi observada por meio de uma entrevista, seguindo os procedimentos da entrevista antropológica, porém utilizando um tempo bem mais curto se comparado ao tempo utilizado na entrevista antropológica. Nosso objetivo com a entrevista 
de recepção foi buscar uma lógica, e "essa lógica é a perspectiva do informante" (GUBER, 2004, p. 213).

\subsection{Participantes}

Para o desenvolvimento da pesquisa foram escolhidas duas participantes surdas, professoras, uma da universidade e outra de uma escola pública de surdos. A priori, nosso propósito era ter mais informantes, mas levando-se em consideração o tempo exigido para esse tipo de pesquisa, só foi possível contar com as duas referidas participantes.

As duas informantes possuem históricos bem parecidos: a surdez de ambas é severa, são fluentes em Libras e a aprenderam aos 14 anos, são ambas filhas de ouvintes e possuem nível superior completo e pós-graduação. As duas também costumam ir ao cinema e gostam muito de assistir televisão, principalmente novelas e filmes. Utilizaremos aqui as siglas P1 para a primeira participante e P2 para a segunda.

Em relação ao nível de escolaridade, P1 é formada em LetrasLibras com mestrado em Linguística pela Universidade Federal do Ceará (UFC). Atualmente é professora do curso de Letras-Libras da UFC. P2 formou-se em Pedagogia e Letras-Libras (UFC), fez pósgraduação em Gestão e atualmente é professora de Libras de uma escola pública de surdos em Fortaleza, o Instituto Cearense de Educação dos Surdos (ICES). As duas revelaram que conseguem ler e escrever textos em língua portuguesa. Também explicaram que apesar de conseguirem ler textos em português sentem dificuldade para ler as legendas das programações televisivas.

\subsection{Questionário pré-coleta}

Este questionário foi elaborado com o intuito de traçar um perfil das informantes. Para compreendermos melhor a relação dos surdos com a mídia televisiva, pautamo-nos também nas informações analisadas e observadas pela entrevista filmada. 


\subsection{Relato retrospectivo}

O relato retrospectivo consistiu na entrevista filmada com as informantes. Essa entrevista teve seus temas pré-elaborados, mas estes foram modificados ou reestruturados durante a entrevista. O objetivo era permitir que as entrevistadas pudessem sentir-se livres para dialogar sobre suas experiências. As interferências durante a entrevista eram geradas para obter mais informações sobre a temática abordada. Cada entrevistada teve apenas um encontro conosco, que durou de uma a duas horas. As entrevistas foram realizadas nos ambientes sugeridos pelas próprias informantes, individualmente: uma teve lugar no laboratório da UECE e a outra no ICES. As filmagens ocorreram com a permissão das entrevistadas. A conversa foi realizada em Libras com o auxílio de um intérprete.

\subsection{Procedimentos}

Iniciamos a entrevista solicitando às informantes que nos relatassem como haviam aprendido a Libras e suas histórias em relação às escolas por onde haviam passado. Depois conduzimos a conversa para programações televisivas e cinema, buscando informações sobre como as legendas apresentadas pela televisão brasileira têm dado acesso à informação e ao lazer dos surdos. Não apresentamos às informantes nenhuma programação televisiva com legendas. Nosso propósito era deixar cada informante livre para falar sobre sua cultura, sua vida, seu lazer. Só finalizamos a entrevista quando percebemos que havíamos obtido um número razoável de informações sobre a recepção de legendas.

\section{Análise dos dados}

Para a análise dos dados fizemos inicialmente a transcrição das entrevistas, observando as dificuldades que as informantes nos relataram sobre a leitura das legendas nas programações televisivas brasileiras. Dessa forma, buscamos relacionar todas as informações com os gêneros televisivos: programas políticos e propagandas 
comerciais. Também fizemos uma reflexão sobre as experiências das entrevistadas com os programas que já estão sendo legendados pela televisão brasileira usando as técnicas closed caption e respeaking. As informações apresentadas serão confrontadas com o suporte teórico mostrado nas pesquisas em legendagem.

Conforme já foi dito anteriormente, nosso propósito foi usar as ferramentas fornecidas pela entrevista em recepção e com isso compreender melhor a cultura dos informantes surdos, bem como analisar e entender como a televisão brasileira tem chegado à comunidade surda.

A primeira observação a ser feita é o fato de que as duas informantes aprenderam a Libras, sua L1, com apenas 14 anos. Além disso, frequentaram escolas de ouvintes que estavam sempre preocupadas em oralizá-las e ensiná-las a escrever palavras em português por meio de inúmeras cópias.

Estudei por três anos numa escola de ouvintes, mas somente copiava e era oralizada por uma fonoaudióloga. Foram anos e anos sempre copiando. No ensino médio, no primeiro ano, eu fui para uma associação de surdos e comecei a aprender a Libras. Todos sinalizavam, menos eu, fiquei espantada. Eu queria oralizar. Aprendi muito pouco na escola. (P1, 34 anos)

As duas informantes acreditam que esse tempo sem o acesso à L1 (Libras) dificultou muito a aprendizagem da língua portuguesa. Em vez de colaborar com sua inclusão entre os ouvintes, excluía-as ainda mais. A escola tornara-se apenas um ambiente de cópias. Para as duas, os estudos em L2 só se tornaram significativos quando começaram a encontrar outros surdos na Associação de Surdos e assim aprenderam a Libras e se fortaleceram na sua própria cultura.

As duas também ressaltaram que com muita dificuldade e alguns atrasos conseguiram concluir o curso superior. Acreditam que o fato de terem aprendido a Libras apenas na adolescência pode ter contribuído para o atraso na aprendizagem da L2, uma vez que, conforme pesquisas na área, é extremamente importante a aquisição da L1 ainda na infância para garantir a aprendizagem da L2 (KATO, 1999). 
Em relação às programações televisivas, as duas falaram que costumam assistir novelas com as legendas apresentadas pela Rede Globo em closed caption, mas não se sentem confortáveis por estas serem muito longas e rápidas. $\mathrm{P} 1$ afirmou que muitas vezes se prende à imagem, porque fica cansada de ler tantas linhas. "As legendas grandes e com letras pequenas ou legendas pequenas são difíceis de ler" (P1)

Tem legendas de novelas. Têm surdos que conhecem algumas palavras. Têm alguns surdos que não sabem português. É muito difícil. Tem alguns surdos que gostam de ler, mas em relação às novelas, as legendas são muito rápidas. Têm palavras que os surdos não conhecem. Quando o surdo não sabe o português, para ele, o visual é mais importante do que a legenda. Na minha opinião, para o surdo entender mais fácil, deveria ter um intérprete lá. Eu até prefiro os dois. Mas quando a legenda é muito rápida, o intérprete ajuda. Eu assisto à assembleia. Eu entendo. (P2, 31 anos)

Quando P2 fala de intérprete na programação ela se refere à janela de Libras.

Em algumas programações, principalmente as políticas, é disponibilizado um espaço no formato de um quadro no canto inferior direito da tela com um intérprete da Libras. Para P1, esse recurso é bom, mas não tem sido usado adequadamente.

A janela, às vezes, é pequena e eu não consigo ver. As mãos e a impressão facial ficam pequenas e não dá para ver. Por exemplo, a propaganda da prefeitura. É muito pequena a janela. Eu me esforço muito para enxergar as mãos mexendo muito rápido. Eu preciso de lupa. (P1)

Por isso enfatizamos a importância de questionar e buscar saber com os próprios surdos se as ferramentas usadas para tradução audiovisual estão sendo confortáveis e suficientes para a comunicação entre o mundo dos ouvintes e o dos surdos.

Quando conversamos sobre as propagandas comerciais, que em sua maioria ainda não são legendadas, P1 respondeu: "Há muitas propagandas, mas não têm legenda. Eu não sei o que elas estão Horizontes de Linguística Aplicada, ano 12, n. 1, 2013 
falando. Promoção, eu não sei. A minha mãe me fala”. P2 afirmou que quando algo chama sua atenção na imagem de uma propaganda ela procura na internet o restante da informação. O marido de P2 é formado em computação e trabalha com internet, então ela sempre está pesquisando na internet informações sobre compra e venda de produtos. As propagandas televisivas apenas sinalizam a ela uma promoção que deveria pesquisar.

A verdade é que a gente perde muita coisa. [...] O surdo vê a imagem e quando chega em casa tem que acessar a internet. Acessa a internet para saber a promoção. Ler a promoção. A televisão em si não ajuda. Os surdos perdem muitas informações. Só tem legendas para as coisas mais importantes. Como novela, jornal e política. Por isso, o meu esposo ama a tecnologia. Para obter algumas informações ele acessa a internet. Qualquer promoção, ele vai e me avisa. Mas a televisão em si não ajuda. (P2)

Outro fato importante observado por meio dos relatos é que os recursos de tradução audiovisual parecem ser insignificantes quando a programação em si não reconhece que há espectadores surdos. A única propaganda política, dentre as já apresentadas em Fortaleza (CE), que seguiu os parâmetros de legendagem do modelo europeu e dos modelos testados pelo grupo Lead foi a propaganda do PSOL. Contudo, P2 reclama que não conseguia ler bem a legenda porque a imagem, que apresentava muitas informações visuais, a confundia e a deixava cansada.

Às vezes, as cores da imagem atrapalham a legenda. Por exemplo, um programa político... vou dar um exemplo... Renato, vereador. Ele tem lá aquelas imagens, atrapalha tanto... atrapalha na legenda, eu não vejo. tem lá o sol, atrapalha tanto. Eu vejo aquelas imagens e não entendo. (P2)

A partir dessa declaração de P2 e de outras semelhantes de surdos entrevistados em outras pesquisas, uma nova preocupação passou a fazer parte de nossas pesquisas em tradução audiovisual por meio de legendas: os responsáveis pelas programações televisivas 154

Horizontes de Linguística Aplicada, ano 12, n. 1, 2013 
também precisam reconhecer as necessidades dos espectadores surdos para lhes apresentar programas cuja imagem não prejudique a leitura das legendas. $\mathrm{O}$ excesso de informação visual também é muito comum nas propagandas comerciais, uma vez que o tempo para apresentar o produto é curto, geralmente 30 segundos. Assim, os produtores costumam usar todo o espaço da tela com informações verbais sobre o produto, deixando pouco ou praticamente nenhum espaço para a legenda na tela. E, conforme afirmado por P2, o excesso de informação visual compromete a leitura da legenda, mesmo que ela apresente velocidade de leitura adequada à capacidade leitora dos surdos e sincronia com o tempo dos diálogos. Conforme De Bruycker e D'Ydewalle (2003), o espectador surdo precisa dividir e desviar sua atenção entre a imagem e a legenda, e tal tarefa torna-se complexa quando não se pode ter o input sonoro. As informações apenas devem ser resgatadas da imagem e da legenda, e a imagem não deve causar incômodos à leitura da legenda.

As informantes afirmaram que sentem dificuldades de leitura com legendas roll- up e pop-on. As duas também disseram que há muitos surdos que ainda não leem textos em língua portuguesa, por isso, se os programas apresentarem apenas a legenda como recurso, ainda será insuficiente. Conforme P1, legendas e janela de Libras deveriam ser apresentadas em todos os programas, para os surdos não se sentirem excluídos. Por sua vez, P2 disse que se deve dar prioridade à janela de Libras, mas reconhece que há ensurdecidos que têm a língua portuguesa como L1 porque só perderam a audição depois de terem sido alfabetizados em língua portuguesa. Ela também lembrou que o canal da Assembleia Legislativa só apresenta a janela de Libras e que precisa ter as duas ferramentas de tradução (janela de Libras e legenda).

As duas também reconheceram a cor amarela como a ideal para legendas, e o número de linhas, apenas duas. Quando vão ao cinema, dizem que não se sentem confortáveis com a legenda branca, por isso preferem assistir a filmes em casa, pois a cor da legenda em DVD é amarela e, segundo elas, mais visível. Ainda há o recurso, no DVD, de voltar o filme para rever alguma informação perdida. P2 também revelou que o tamanho da tela dificulta a leitura da legenda. Sobre cinema nacional, elas se mostraram indignadas com o fato de os 
filmes nacionais não oferecerem sessões legendadas nos cinemas brasileiros. Disseram que se sentem excluídas, como espectadoras, das estreias de filmes nacionais no cinema. Dessa forma, e diferente dos ouvintes, elas sempre têm de esperar o lançamento em DVD.

As informações apresentadas nas entrevistas levam-nos a observar que as mídias de comunicação televisivas ainda estão distantes de um padrão inclusivo e, principalmente, que as técnicas de tradução precisam ser analisadas e testadas levando em consideração os anseios e as necessidades dos surdos.

\section{Considerações finais}

Com base nas informações obtidas por intermédio das entrevistas realizadas, pode-se afirmar que a aprendizagem tardia da Libras das duas entrevistadas fez com que tivessem dificuldades com a aprendizagem da língua portuguesa. Elas se sentiram mais incluídas e fortalecidas quando começaram a se comunicar com outros surdos por meio de Libras.

Para os espectadores investigados nesta pesquisa, as legendas da televisão brasileira atual e a janela de Libras são importantes para os surdos terem acesso à informação. Contudo, elas ressaltam que essas técnicas ainda não traduzem suficientemente as informações auditivas e visuais das programações. Elas entendem que as técnicas de tradução audiovisual apresentadas até o momento precisam ser repensadas e analisadas por meio de pesquisas. A crítica maior foi com relação à velocidade e à extensão das legendas disponibilizadas por meio de closed caption e com relação ao tamanho da janela de Libras.

Com relação às propagandas de anúncios publicitários televisivos, a grande crítica foi justamente a ausência de legendas. De fato, esse gênero precisa ter maior atenção dos responsáveis pelos meios de comunicação brasileiros, principalmente a televisão. É preciso, portanto, que mais pesquisas sejam direcionadas a esse tema e que esse tipo de legendagem comece a ser cada vez mais produzida a fim de fomentar a inclusão dos surdos.

Com a pesquisa de recepção foi possível compreendermos que a tradução audiovisual por legendas deve também se preocupar com o 
espaço dividido com a imagem. Ou seja, os programadores de propagandas políticas e comerciais devem igualmente reconhecer os espectadores surdos como sujeitos que necessitam das informações televisivas traduzidas e que precisam ter espaço na tela para compreender as imagens e as legendas. Ficou claro também que a cor amarela para a fonte das legendas é a cor ideal, segundo as informantes. Para elas, a cor branca pode atrapalhar o processo de leitura. Essa é ainda uma questão controversa, visto que em outras pesquisas realizadas pelo grupo Lead a legenda branca foi a escolhida como a ideal.

Foi possível observar também, por intermédio dos relatos, que tanto as legendas do tipo rollup como as do tipo pop-on apresentam problemas para as duas participantes. Estas enfatizaram também a importância de serem disponibilizadas as duas formas de tradução audiovisual: as legendas e a janela de Libras. Assim, os surdos que não dominam muito bem a língua portuguesa são beneficiados, bem como aqueles que não dominam a Libras e podem ler as legendas, o que ocorre principalmente entre os ensurdecidos.

É importante deixar claro que o trabalho de tradução tanto em Libras quanto em língua portuguesa deve ser desempenhado por profissionais formados ou especializados em tradução, pois, conforme foi dito anteriormente, a LSE e a interpretação em Libras são formas de tradução complexas em virtude de envolverem línguas e culturas diferentes.

Acreditamos que as reflexões abordadas neste trabalho sejam relevantes às pesquisas em tradução audiovisual. Entretanto, trata-se de uma pesquisa piloto, com apenas duas participantes, sendo, portanto, uma pequena contribuição para que pesquisas maiores possam ser realizadas e apresentem conclusões e dados mais aprofundados. Dessa forma, sugerimos que outras pesquisas de recepção em legendagem para surdos sejam realizadas, com um número maior de informantes, fomentando assim as pesquisas na área. 


\section{Referências}

ARAÚJO, Vera L. S. Closed subtitling in Brazil. In: ORERO, Pilar (Org.). Topics in audiovisual translation. Amsterdã: John Benjamins Publishing Company, v. 1, 2004. p. 199-212.

A legendagem para surdos no Brasil. In: LIMA, Paula L. C.; ARAÚJO, Antonia D. (Orgs.). Questões de linguística aplicada: miscelânea. Fortaleza: EdUECE, 2005. p. 163-188.

- Subtitling for the deaf and hard-of-hearing in Brazil. In: ORERO, Pilar; REMAEL, Aline (Orgs.). Media for all: subtitling for the deaf, audio description and sign language. Kenilworth, New Jersey: Rodopi, v. 30, 2007. p. 99-107.

- Por um modelo de legendagem para surdos no Brasil. Tradução e Comunicação: Revista Brasileira de Tradutores, n. 17, p. 59-76, 2008.

- In search of SDH parameters for Brazilian party political broadcasts. The sign language translator and interpreter. Manchester, St. Jerome Publishing Company, v. 3, n. 2, p. 157-175, 2009.

ARAÚJO, Vera L. S.; CHAVES, Élida G. Etiquetas de segmentação: uma proposta para análise da segmentação em legendas intralinguísticas de filmes brasileiros. In: XI ENCONTRO DE LINGUÍSTICA DE CORPUS (ELC), 2012, São Carlos. Anais do XI ENCONTRO DE LINGUÍSTICA DE CORPUS (ELC). São Carlos, 2012. Disponível em: <http://www.nilc.icmc.usp.br/elcebralc2012/anais/completos/103954.pdf>. Acesso em: 10 jan. 2014.

ARAÚJO, Vera L. S.; NASCIMENTO, Ana K. P. Investigando parâmetros de legendas para surdos e ensurdecidos no Brasil. Tradução em Revista, v. 2, n. 11, p. 1-18, 2011. Disponível em: <http://www.maxwell.lambda.ele.puc-rio.br/18862/18862〉. Acesso em: 3 mar. 2012.

ARAÚJO, Vera L. S.; VIEIRA, Patrícia A.; MONTEIRO, Silvia M. M. Legendagem para surdos e ensurdecidos (LSE): um estudo de 158 Horizontes de Linguística Aplicada, ano 12, n. 1, 2013 
recepção com surdos da Região Sudeste. Tradterm, v. 22, p. 283-302, 2013.

BARSI-LOPES, Daniel. Cidadania midiatizada: o programa Linha Direta sob a ótica da recepção. In: XXXI CONGRESSO BRASILEIRO DE CIÊNCIAS DA COMUNICAÇÃO, 2008, Natal. Anais do XXXI CONGRESSO BRASILEIRO DE CIENCIAS DA COMUNICAÇÃO. Natal, 2008. Intercom: Sociedade Brasileira de Estudos Interdisciplinares da Comunicação, 2008. Disponível em: <http://www.intercom.org.br/papers/nacionais/2008/resumos/R3-09681.pdf>. Acesso em: 12 de jan. 2012.

CHAVES, Élida G. Legendagem para surdos e ensurdecidos: um estudo baseado em corpus da segmentação nas legendas de filmes brasileiros em DVD. 2012. 126f. Dissertação (Mestrado em Linguística Aplicada) - Faculdade de Letras, Universidade Estadual do Ceará, Fortaleza, 2012.

D'YDEWALLE, Gerry et al. Reading a message when the same message is available auditorily in another language: the case of subtitling. In: O'REGAN, K.; LÉVY-SCHOEN, A. (Eds.). Eye movements: from physiology to cognition. Amsterdam; New York: Elsevier Science Publishers, 1987. p. 313-321.

DE BRUYCKER, Wim; D'YDEWALLE, Gerry. Reading native and foreign language television subtitles in children and adults. In: HYONA, J.; RADACH, R.; DEUBEL, H. (Ed.). The mind's eye: cognitive and applied aspects of eye movements. Oxford: Research Lirias, 2003. p. 671-684.

DE LINDE, Zoe; KAY, Michael. The semiotics of subtitling. Manchester: St. Jerome Publishing, 1999.

DÍAZ CINTAS, Jorge; REMAEL, Aline. Audiovisual translation: subtitling. Manchester; Kinderhook: St. Jerome Publishing, 2007.

FRANCO, Eliana; ARAÚJO, Vera. L. S. Reading television: checking deaf people's reactions to closed subtitling in Fortaleza, Brazil. In: GAMBIER, Y. (Org.). The Translator, v. 9, n. 2, p. 249-267, 2003.

Horizontes de Linguística Aplicada, ano 12, n. 1, 2013 
GUBER, Rosana. El salvaje metropolitano. Reconstrucción del conocimiento social en el trabajo de campo. Buenos Aires: Paidós, 2004. p. 203-249.

IVARSSON, Jan. Subtitling for the media: a handbook of an art. Stockholm: Transedit, 1992.

IVARSSON, Jan; CARROL, Mary. Subtitling. Simrishamn, Sweden: Grapho-Tryck AB, 1998.

KARAMITROGLOU, Fotios. A proposed set of subtitling standards in Europe. Translation Journal, v. 2, n. 2, p. 1-15, 1998. Disponível em: <http://translationjournal.net/journal//04stndrd.htm> Acesso em: 20 dez. 2013.

KATO, Mary. $O$ aprendizado da leitura. 5 ed. São Paulo: Martins Fontes, 1999.

LOPES, Maria I. V. Uma agenda metodológica presente para a pesquisa de recepção na América Latina. In: JACKS, Nilda (Org.). Análisis de recepcion en América Latina. Quito: Editorial Quipus, 2011. p. 409-428.

NEVES, Joselia. Audiovisual translation: subtitling for the deaf and the hard-of-hearing. 357f. Tese (Doutorado) - School of arts, Roehampton University, Unversity of Surrey. London, 2005.

PEREGO, Elisa. Evidence of explicitation in subtitling: towards a categorization. Across Languages and Cultures, Budapest, v. 4, n. 1. p. 63-88, 2003.

- What would we read best? Hypotheses and suggestions for the location of line breaks in film subtitles. The Sign Language Translator and Interpreter. Manchesterp, v. 2, n. 1. p. 35-63, 2008.

RIBAS, Marta; Romero FRESCO, Pablo; A. A practical proposal for the training of respeakers. The Journal of Specialised Translation, n. 9, p. 106-127, 2008. Disponível em: 
Vera L. S. Araújo; Silvia M. M. Monteiro; Patrícia A. Vieira

<http://www.jostrans.org/issue10/art_arumi.php>. Acesso em: 20 mar. 2012.

VIEIRA, Patrícia A. O uso dos gêneros quadrinho e tirinhas no ensino de leitura em português como segunda língua: por uma abordagem bilíngue para os surdos. 2009. 216f. Dissertação (Mestrado em Linguística Aplicada) - Centro de Humanidades, Pós-Graduação em Linguística Aplicada, Universidade Estadual do Ceará, Fortaleza, 2009.

Submetido em: 11/01/13

Aceito em: 03/04/14

Title: Subtitling of political campaigns and advertisements for the Brazilian television: a reception research 